\title{
INDOOR MASS CONCENTRATIONS OF PARTICULATE MATTER IN HOSPITAL ENVIRONMENT
}

\author{
GAIDAJIS G. ${ }^{1, *}$ \\ ANGELAKOGLOU $\mathrm{K}^{1}$
}

\author{
${ }^{1}$ Department of Production Engineering and Management \\ School of Engineering, Democritus University of Thrace, Greece \\ University Campus, 12 Vasilisis Sofias, Building 1, Xanthi, GR-67100, Greece
}

Received: 20/09/2012

Accepted: 01/10/2014

Available online: 01/10/2014 *to whom all correspondence should be addressed: e-mail:geogai@pme.duth.gr

\section{ABSTRACT}

The assessment of the indoors air quality where people usually spend extended time periods, especially for sensitive population groups such as patients during their hospitalization, is of major importance. Ensuring a safe level of air quality in these indoor environment serves as an amelioration factor for human health not only for the often habitués of those indoors places, but also for the working personnel that spend more than $90 \%$ of their time indoors. In that aspect the concentration of coarse $\left(\mathrm{PM}_{10}\right)$ and fine $\left(\mathrm{PM}_{2.5}, \mathrm{PM}_{1.0}\right)$ particulate matter was measured in two Intensive Care Units (ICU), with different spatial and trespassing characteristics, of the Democritus University Hospital situated at Alexandroupolis, Greece. The measurements were conducted with the application of two portable aerosol monitoring equipment (TSI DustTrak 8520 and Grimm 107).

The results indicated that the 24-h average concentrations were below the indicative limits proposed by the World Health Organization (WHO) (50 and $25 \mu \mathrm{g} \mathrm{m} \mathrm{m}^{-3}$ for $\mathrm{PM}_{10}$ and $\mathrm{PM}_{2.5}$ respectively). Relatively elevated instant concentration levels $\left(>100 \mu \mathrm{g} \mathrm{m}^{-3}\right)$ were also recorded during specific activities and in conjunction with the temporal variation of the observed concentration levels raised questions regarding the side effects of cleaning activities.

KEYWORDS: coarse and fine particulate matter, intensive care units, air quality

\section{Introduction}

A degraded indoors air quality (IAQ) is potentially associated with outdoors concentration levels of hazardous substances, insufficient air exchange rate, limited spacing for air mixing and presence of hidden continuous emitting sources. A well accepted indicator of the indoor air quality is concentration levels of particulate matter. The significance of particulate matter to human health is well documented since one of the key features of particulate matter is its characteristic ability to act as a transportation medium of hazardous substances and chemicals into the human respiratory system.

Good indoor air quality is more important in hospital environment than in many other buildings (Hellgren et al., 2011). People who are hospitalized are particularly vulnerable and sensitive to airborne substances. A clean environment helps patients since the contagion of potentially dangerous agents is avoided. The use of chemicals for disinfection and sterilization and the treatment means of patients further contribute to the aggravation of IAQ in hospital environment. 
An increasing number of studies deal with the assessment of IAQ in hospital environment. In some cases, the air and surfaces in hospital settings were assessed to reveal the presence of pathogenic viruses, bacterial etc. (Carducci et al., 2011), whereas other studies focused on the bioaerosol quality in operating theatres, hospital rooms and maternity wards (Ortiz et al., 2009), or the characterization of the predominant aerobic bacteria and fungi (Sudharsanam et al., 2008). Anaesthetic gases and other indoor chemical compounds were also analyzed in operating rooms (Dascalaki et al., 2008).

Unexpectedly, in most studies it was found that personnel are exposed to relatively poor IAQ. Insufficient air exchange, bad space ergonomics and poor maintenance of ventilation systems were identified as the main reasons for poor IAQ performance (Dascalaki et al., 2008). It is further suggested that the role of efficient ward ventilation may have been underestimated (Beggs et al., 2008). A significant misstep is that ventilation systems for general wards and patient rooms are modelled with the application of similar criteria and assumptions used for non-clinical spaces (Beggs et al., 2008). Management strategies and techniques are available in order to successfully control IAQ in hospitals (Leung and Chan, 2006).

The significance of satisfying IAQ for minimizing complaints from occupants is well documented in relative studies regarding hospital environment (Dascalaki et al., 2009; Hellgren et al., 2008). Dustiness is one of the most common complaints reported among hospital staff in relation to indoor air (Hellgren et al., 2008). Few studies however, were identified by the authors that assess the indoor air quality in hospital environment in terms of particulate matter. In that aspect the concentration levels of coarse $\left(\mathrm{PM}_{10}\right)$ and fine $\left(\mathrm{PM}_{2.5}, \mathrm{PM}_{1.0}\right)$ particulate matter were measured in two intensive care units (ICU), with different spatial and trespassing characteristics, of the Democritus University General Hospital of Alexandroupolis, Greece. The results presented in this study could be characterized as a screening of the existing concentration levels in order to identify the necessity and the characteristics of a future longterm campaign.

\section{MATERIALS AND METHODS}

\subsection{Sampling Devices}

Two different sampling devices were used for the conduction of the measurements, in order to ensure the comprehensiveness of the study. Both devices use a light scattering technology to determine mass concentration in real time (in $\mathrm{g} \mathrm{m}^{-3}$ ). The first sampling device was the Grimm dust-monitor Model 107 (GRIMM). GRIMM is a small portable unit used for continuous measurements of aerosols. An internal volume-controlled pump draws the ambient air to be analyzed at a rate of 1.2 litres per minute. The sample passes through the sample cell, past the laser diode detector and is collected onto a 47-mm PTFE filter. The factory calibrations were maintained in order for the measurement to be in accordance with relative European regulation (EN 12341).

The second sampling device was a portable TSI DustTrak Aerosol Monitor, Model 8520 (TSI). For the present study the pre-programmed calibration using the respirable fraction of standard ISO 12103-1, A1 test dust (Arizona Test Dust), was maintained. The sample flow rate was set at 1.7 litres per minute. A flow and a zero check were performed before each use. The TSI instrument can only measure one particulate matter size per time depending on the nozzle applied, in contrast with the GRIMM sampling instrument where $\mathrm{PM}_{10}, \mathrm{PM}_{2.5}$ and $\mathrm{PM}_{1}$ are measured simultaneously.

\subsection{Sampling Area}

The sampling campaign was performed at the Democritus University Hospital at Alexandroupolis, Greece. The specific hospital was built in 2002 and is located approximately $6 \mathrm{~km}$ from the city centre of Alexandroupolis. The relative location of the hospital and the major potential air quality impairment sources (i.e., urban grid, industrial area, highways, etc.) are shown in Figure 1. The hospital has a maximum occupancy of 671 beds and covers a total area of approximately $93,500 \mathrm{~m}^{2}$. Access to the hospital is easy due to its proximity to the main roads and the frequent bus transportation scheme. 


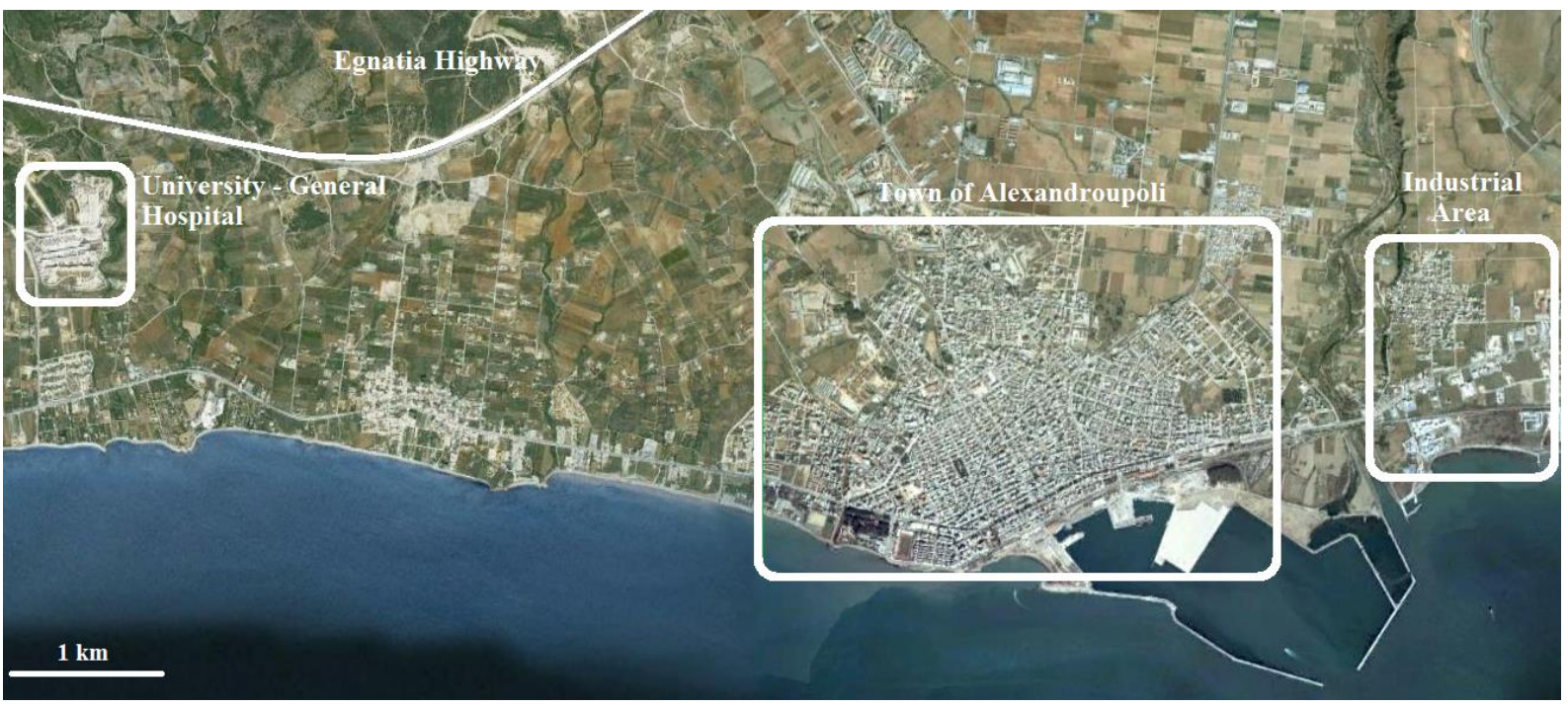

Figure 1. Relative location of the hospital in the wider area of Alexandroupolis.

More specifically, the sampling was conducted in the two intensive care units (ICU) of the hospital. The general characteristics of the units are presented in Table 1. The first ICU (ICU-1) is used for general medical incidents whereas the second ICU (ICU-2) focuses on heart surgery patients. The plan view of each ICU is given in Figure 2.

Table 1. General characteristics of the intensive care units.

\begin{tabular}{lccccc}
\hline Sampling area & $\begin{array}{c}\text { Area } \\
\left(\mathrm{m}^{2}\right)\end{array}$ & $\begin{array}{c}\text { Volume } \\
\left(\mathrm{m}^{3}\right)\end{array}$ & $\begin{array}{c}\text { Windows area } \\
\left(\mathrm{m}^{2}\right)\end{array}$ & $\begin{array}{c}\text { Bed occupancy during } \\
\text { sampling }\end{array}$ & $\begin{array}{c}\text { Total capacity } \\
\text { (in beds) }\end{array}$ \\
\hline ICU-1 & 308 & 924 & 15.1 & 10 & 16 \\
\hline ICU-2 & 153 & 459 & 10.2 & 4 & 6 \\
\hline
\end{tabular}

The ICUs are positively pressurized isolation rooms whereas the air exchange with the ventilation system of the hospital is not allowed. During sampling, the air pressure in the ICUs was equal to the atmospheric pressure since windows were frequently left open. The ICUs personnel varies among 3-4 doctors, 3-5 nurses and 1-2 ward assistants/cleaners depending on the time of the day and occupancy. During morning hours, there are also groups of 8-10 medical students who attend the treatment process. The ICUs are cleaned two times during the morning and once in the afternoon. The patient wards are cleaned once a day. The building shell is made of concrete and bricks whereas the patient wards are separated with removable walls made from gypsumboard, aluminum framing and glass.
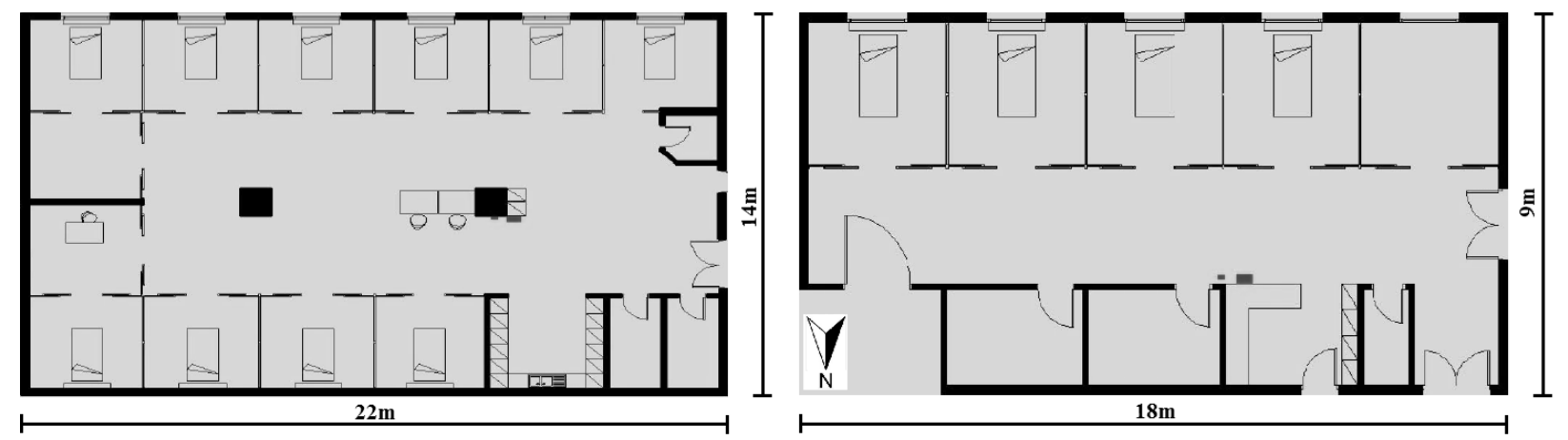

Figure 2. Plan view of the intensive care units (ICU-1-left and ICU-2-right). 


\subsection{Sampling profile}

The sampling campaign was conducted during the period 10/05/2011 to 14/05/2011. Prior and after each indoor sampling campaign the outdoor air was sampled with TSI, when possible, for a short period in order to indicatively record the outdoors concentrations of particulate matter. The monitoring device was placed as close to the centre of every room as possible and in a convenient height from the ground in order to simulate the inhalation height. The sampling profile of the measurements is presented in Table 2. The prevailing weather conditions during the measurement period are presented in Table 3 (HNMS, 2011).The aim of the sampling campaign was to obtain data for at least 24 hours for every ICU with all instruments.

Table 2. Sampling profile-timetable of the campaign performed.

\begin{tabular}{|c|c|c|c|c|c|c|c|c|}
\hline \multirow[t]{3}{*}{ Sampling } & \multicolumn{4}{|c|}{ ICU-1 } & \multicolumn{4}{|c|}{ ICU-2 } \\
\hline & \multicolumn{4}{|c|}{ Sampling equipment and duration } & \multicolumn{4}{|c|}{ Sampling equipment and duration } \\
\hline & Grimm & $(\mathrm{h}: \mathrm{m})$ & TSI & (h:m) & Grimm & (h:m) & TSI & (h:m) \\
\hline $10 / 05 / 2011$ & $\mathrm{PM}_{10-2.5-1}$ & $(11: 14)$ & $\mathrm{PM}_{10}$ & (09:55) & & & & \\
\hline $11 / 05 / 2011$ & $\mathrm{PM}_{10-2.5-1}$ & $(24: 00)$ & $\mathrm{PM}_{10-2.5}$ & $(20: 34)$ & & & & \\
\hline $12 / 05 / 2011$ & $\mathrm{PM}_{10-2.5-1}$ & $(16: 20)$ & $\mathrm{PM}_{2.5}$ & $(17: 22)$ & $\mathrm{PM}_{10-2.5-1}$ & $(07: 26)$ & $\mathrm{PM}_{10}$ & $(06: 17)$ \\
\hline $13 / 05 / 2011$ & & & & & $\mathrm{PM}_{10-2.5-1}$ & $(24: 00)$ & $\mathrm{PM}_{10-2.5}$ & $(23: 38)$ \\
\hline $14 / 05 / 2011$ & & & & & $\mathrm{PM}_{10-2.5-1}$ & $(17: 20)$ & $\mathrm{PM}_{2.5}$ & $(18: 02)$ \\
\hline Total & & $(51: 34)$ & & $(47: 51)$ & & $(48: 46)$ & & $(47: 57)$ \\
\hline
\end{tabular}

Table 3. Prevailing weather conditions during the measurement period (HNMS, 2011).

\begin{tabular}{rccccc}
\hline Date & $\begin{array}{c}\text { Avg. temp. } \\
\left({ }^{\circ} \mathrm{C}\right)\end{array}$ & $\begin{array}{c}\text { Avg. humidity } \\
(\%)\end{array}$ & $\begin{array}{c}\text { Sunshine } \\
\text { (hours) }\end{array}$ & $\begin{array}{c}\text { Avg. wind } \\
\text { speed }\left(\mathrm{m} \mathrm{s}^{-1}\right)\end{array}$ & Wind direction \\
\hline $10 / 05 / 2011$ & 16.95 & 55.24 & 8.90 & 3.28 & NE \\
$11 / 05 / 2011$ & 16.80 & 58.88 & 10.50 & 4.31 & NNE \\
$12 / 05 / 2011$ & 15.25 & 71.82 & 10.30 & 3.21 & $\mathrm{NE}$ \\
$13 / 05 / 2011$ & 15.85 & 76.81 & 5.20 & 1.61 & $\mathrm{SW}$ \\
$14 / 05 / 2011$ & 18.65 & 55.32 & 7.50 & 1.28 & $\mathrm{SW}$ \\
\hline
\end{tabular}

\section{Results and discussion}

The concentration levels measured during the sampling campaign at ICU-1 and ICU- 2 are summarized in Table 4 and Table 5 respectively. Note that $\mathrm{PM}_{10}$ and $\mathrm{PM}_{2.5}$ concentrations measured with TSI refer to different days.

As a general statement it could be inferred that the concentration levels of particulate matter for both ICU-1 and ICU-2 are satisfactory, being in most cases slightly below the proposed 24-hour average guidelines proposed by the World Health Organization (WHO). The results measured in this study are of the same order of magnitude in comparison with similar studies (Tang et al. 2009; Wan et al. 2011). It should be noted though that different sampling devices, spatial characteristics (population density) and hospital occupancy may significantly affect the results, thus comparisons should not be made hastily.

Significantly elevated instantaneous maximum concentrations were measured however, especially in ICU-1 (2467 $\mathrm{g} \mathrm{m} \mathrm{m}^{-3}$ for PM 10 ). Moreover, an inconsistency of the results derive from the two instruments was observed. Average results from TSI sampling equipment were higher than that of the GRIMM, raising thus questions regarding overestimation/underestimation of the results. On the other hand, GRIMM equipment measured wider concentration ranges, indicating higher sensitivity and ability to 
count wider fluctuations. More data and simultaneous measurements are needed to efficiently reach to safe conclusions.

Table 4. Concentration levels measured in ICU-1 (concentrations in $\mu \mathrm{g} \mathrm{m}^{-3}$ ).

\begin{tabular}{cccccc}
\hline Sampling equipment & $\begin{array}{c}\text { Sampling Duration } \\
(\mathrm{hh}: \mathrm{mm})\end{array}$ & Min. & Max. & Average & Median \\
\hline Grimm 107 & & & & & \\
\hline $\mathrm{PM}_{10}$ & $(51: 34)$ & 9 & 2467 & 44 & 30 \\
\hline $\mathrm{PM}_{2.5}$ & $(51: 34)$ & 7 & 331 & 19 & 14 \\
\hline $\mathrm{PM}_{1}$ & $(51: 34)$ & 5 & 68 & 15 & 11 \\
\hline TSI Dustrak & & & & & \\
\hline $\mathrm{PM}_{10}$ & $(23: 58)$ & 16 & 305 & 59 & 32 \\
\hline $\mathrm{PM}_{2.5}$ & $(23: 53)$ & 13 & 254 & 43 & 34 \\
\hline WHO guidelines*: $\mathrm{PM}_{10}$ & & & & $20 / 50$ & \\
\hline WHO guidelines*: $P M_{2.5}$ & & & & $10 / 25$ & \\
\hline
\end{tabular}

* Annual average / 24-hour average

Table 5. Concentration levels measured in ICU-2 (concentrations in $\mu \mathrm{g} \mathrm{m}^{-3}$ ).

\begin{tabular}{cccccc}
\hline Sampling equipment & $\begin{array}{c}\text { Sampling Duration } \\
\text { (hh:mm) }\end{array}$ & Min. & Max. & Average & Median \\
\hline Grimm 107 & & & & & \\
\hline $\mathrm{PM}_{10}$ & $(48: 46)$ & 8 & 191 & 31 & 27 \\
\hline $\mathrm{PM}_{2.5}$ & $(48: 46)$ & 7 & 59 & 18 & 17 \\
\hline $\mathrm{PM}_{1}$ & $(48: 46)$ & 6 & 54 & 16 & 14 \\
\hline TSI Dustrak & & & & & \\
\hline $\mathrm{PM}_{10}$ & $(23: 51)$ & 14 & 229 & 47 & 42 \\
\hline $\mathrm{PM}_{2.5}$ & $(24: 06)$ & 18 & 276 & 53 & 46 \\
\hline WHO guidelines*: PM $_{10}$ & & & & $20 / 50$ & \\
\hline WHO guidelines*: $\mathrm{PM}_{2.5}$ & & & & $10 / 25$ & \\
\hline
\end{tabular}

* Annual average / 24-hour average

The spatial variation for all measurements is presented in Figure 3 . The most significant conclusions that could be drawn from the specific figure are:

- The widest concentration range was observed for $\mathrm{PM}_{10}$ in ICU1 using the GRIMM sampling equipment $\left(9-2467 \mu \mathrm{g} \mathrm{m}^{-3}\right)$. This is attributed to the elevated instantaneous maximum values measured in ICU1.

- Concentration levels were higher in ICU1 in comparison with ICU2. This could be attributed to the higher occupancy of the ICU1. Although no visitors are allowed in both ICUs, personnel, patients and medical students visiting ICU1 further contribute to the aggravation of the IAQ. In a relative study, a significant association was found between the coarse particle concentration and the number of patient visitors, since it was found that the concentration levels were higher after patient visitation in a medical intensive unit (Tang et al., 2009).

- The concentration levels measured in ICU2 are evenly distributed, since average and median values tend to be equal. 


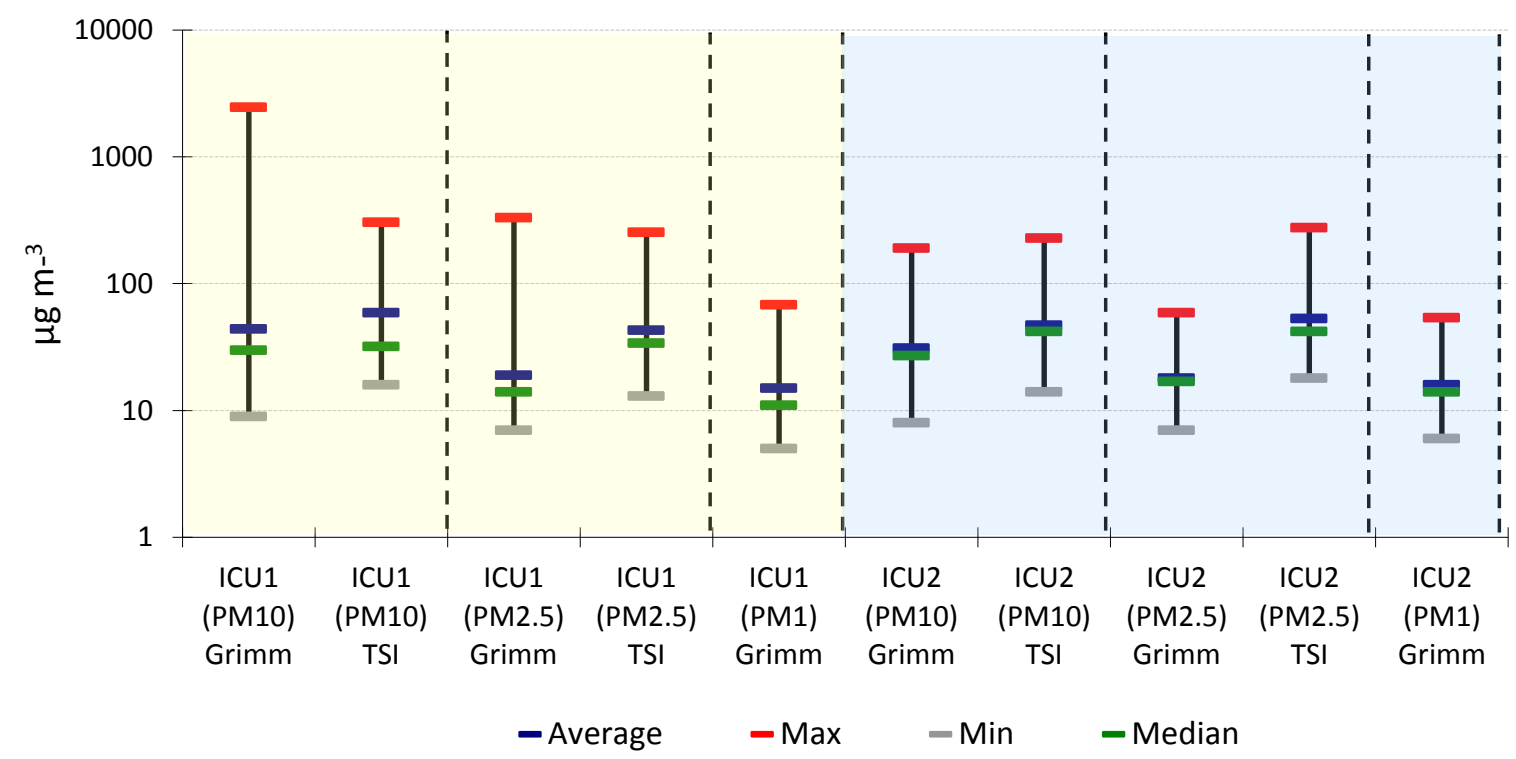

Figure 3. Spatial variation of the PM concentration range

It should be noted that in Figure 3, the sampling duration of concentrations measured with TSI is shorter than that of GRIMM, due to its inability to measure $\mathrm{PM}_{10}, \mathrm{PM}_{2.5}$ and $\mathrm{PM}_{1}$ simultaneously. In that aspect direct comparison between GRIMM and TSI concentrations is not credible. During the experiments, some noticeable instantaneous maximum and periods of elevated concentrations were observed that need to be further analysed. In that aspect the temporal variation of the measurements is presented in Figure 4. A number of conclusions could be drawn from the specific figure:

- The highest values for both ICU-1 and ICU-2 were recorded during the morning shift 107:0015:00) further supporting the notion that trespassing may significantly affect the measurements.

- Most of the measurements performed with the application of TSI are above the indicative limits proposed by WHO (horizontal lines). On the contrary, concentration levels measured with the application of Grimm sampling equipment are most of the time below the guidelines. Further research is needed to justify this variation.

- Cleaning activities seem to highly affect the concentration levels of particulate matter, probably due to re-suspension of settled particulate matter. The cleaning activities are performed three times a day, usually from 07:00 to 09:00, 13:00 to 15:00 and 19:00. As it can be seen in Figure 4, these are the periods where the higher instantaneous maximums are presented. Thus, further research is needed regarding the efficiency of cleaning methods and timing. Actions such as wet cleaning and efficient ventilation during cleaning may have a positive impact in minimizing its negative effect to the increase of indoors concentrations of particulate matter. 
ICU1 (Grimm)

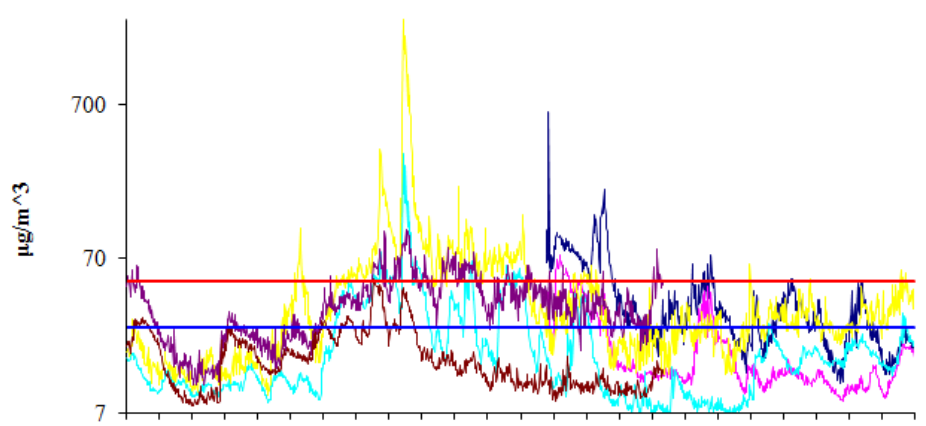

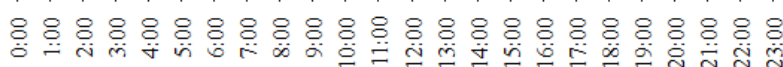

ICU1 (TSI)

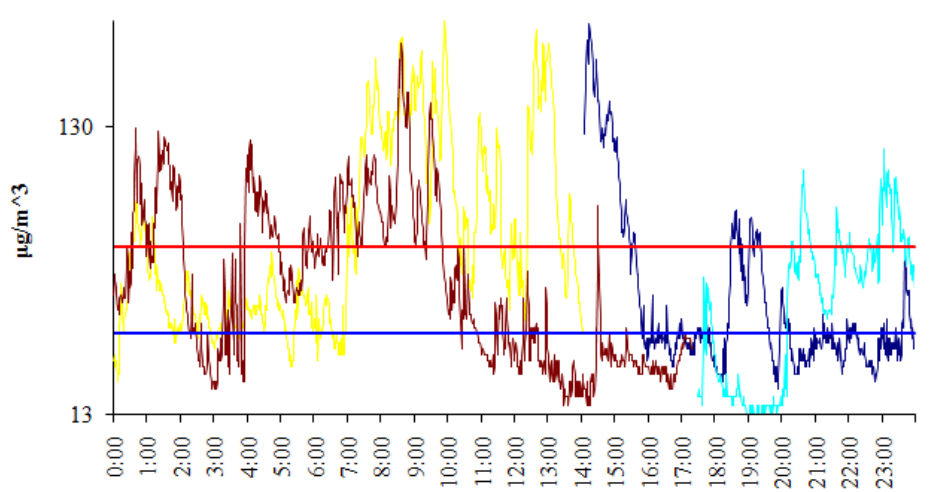

ICU2 (Grimm)

- PM10 (10/05/2011)

-PM2.5 (10/05/2011)

PM10 (11/05/2011)

-PM2. 5 (11/05/2011)

-PM10 (12/05/2011)

-WHO (PM10)

- $\mathrm{WHO}(\mathrm{PM} 2.5)$

- PM10 (10/05/2011)

PM10(11/05/201)

PM2.5(11/05/2011)

PM2.5 (12/05/2011)

-WHO (PM10)

- WHO (PM2.5)
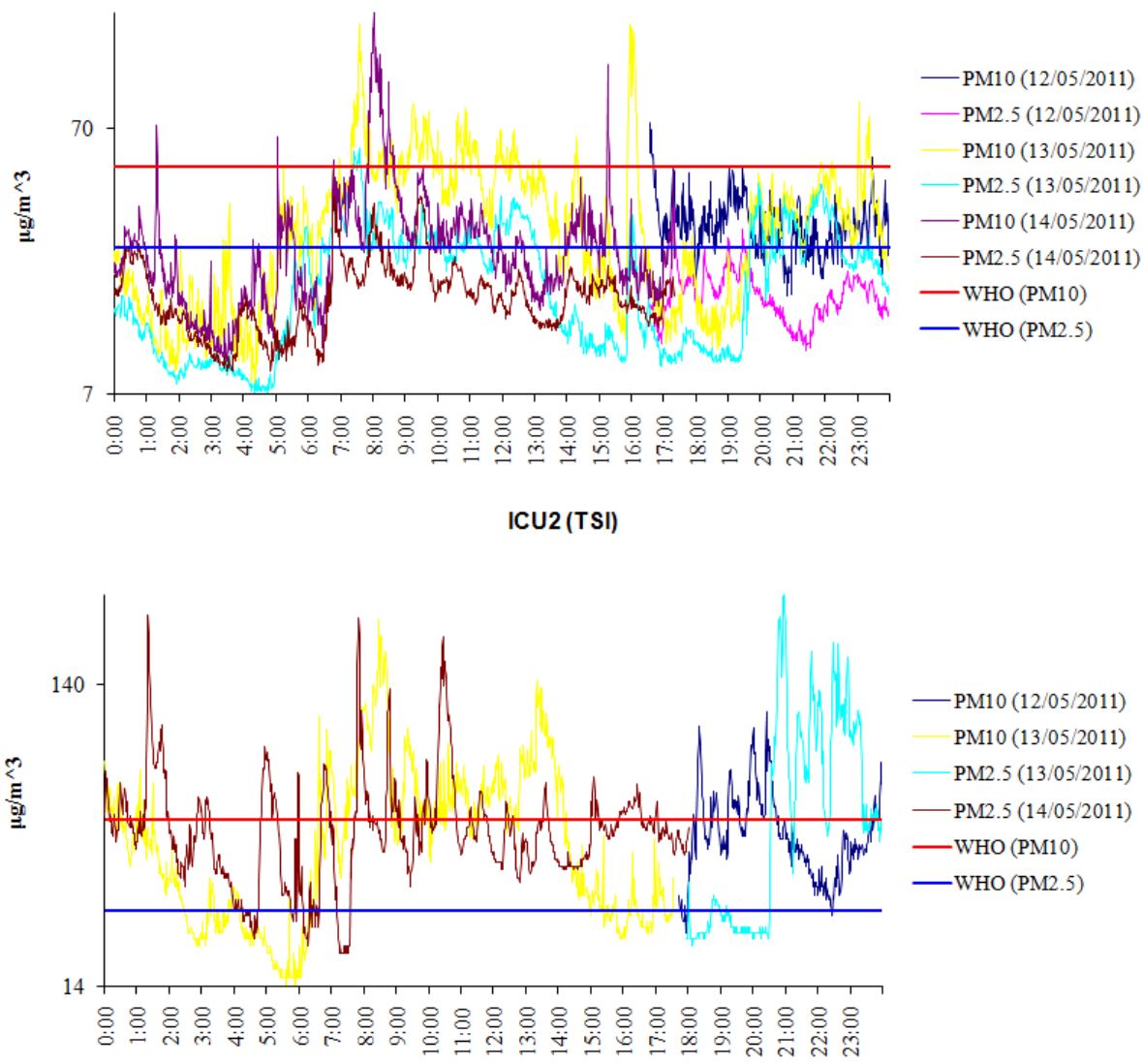

Figure 4. Temporal variation (log scale). 


\section{Conclusions}

Indoor air quality in terms of particulate matter was determined in two intensive care units. The measurements were conducted with the application of two portable aerosol monitoring equipment (TSI DustTrak Aerosol Monitor Model 8520 and Grimm 107). The results indicated that the indoor air quality in terms of average concentration of $\mathrm{PM}_{10}, \mathrm{PM}_{2.5}$ and $\mathrm{PM}_{1}$ were most of the times slightly below the indicative limits $\left(50 \mu \mathrm{g} \mathrm{m}^{-3}\right.$ for $\mathrm{PM}_{10}$ and $25 \mu \mathrm{g} \mathrm{m}^{-3}$ for $\mathrm{PM}_{2.5}$ ) set by the World Health Organisation. Results indicated that a long-term campaign would be of great importance, since high concentration levels of particulate mater were frequently recorded. Dry cleaning activities and intense trespassing seem to have a negative impact to the particulate matter concentration levels. Management strategies and techniques are available in order to successfully control IAQ in hospitals. Therefore, it is anticipated that in order to efficiently reduce the PM concentrations at ICU the joint efforts of technical, healthcare and administrative staff is necessary. Further investigation needs to be undertaken in order to model the behaviour of particulate matter in the indoors areas of hospitals.

\section{ACKNOWLEDGEMENTS}

The authors are grateful to the Director and staff of the hospital for their cooperation during this study.

\section{REFERENCES}

Beggs C.B., Kerr K.G. Noakes C.J., Hathway E.A. and Sleigh P.A. (2008), The ventilation of multiple-bed hospital wards: Review and analysis, Am J Infect Control, 36, 250-259.

Carducci A., Verani M., Lombardi R., Casini B. and Privitera G. (2011), Environmental survey to assess viral contamination of air and surfaces in hospital settings, Journal of Hospital Infection, 77, 242-247.

Dascalaki E.G., Lagoudi A., Balaras C.A. and Gaglia A.G. (2008), Air quality in hospital operating rooms, Building and Environment, 43, 1945-1952.

Dascalaki E.G., Gaglia A.G., Balaras C.A. and Lagoudi A. (2009) ,Indoor environmental quality in Hellenic operating rooms, Energy and Buildings, 41, 551-560.

Hellgren U-M., Palomakl E., Lahtinen M., Riuttala H. and Reijula K. (2008), Complaints and symptoms among hospital staff in relation to indoor air and the condition and need for repairs in hospital buildings, SJWEH Suppl., 4, 58-63.

Hellgren U-M., Hyvarinen M., Holopainen R. and Reijula K. (2011), Perceived indoor air quality, air related symptoms and ventilation in Finnish hospitals, International Journal of Occupational and Environmental Health, 24(1), 48-56.

HNMS (2011) Data provided by Hellenic National Meteorological Service.

Leung M. and Chan A.H.S. (2006), Control and management of hospital indoor air quality, Med. Sci. Monit., 12(3), 17-23.

Ortiz G., Yague G., Segovia M. and Catalan V. (2009), A study of air microbe in different areas of a hospital, Curr. Microbiol., 59, 53-58.

Sudharsanam S., Srikanth P., Sheela M. and Steinberg R. (2008), Study of the indoor air quality in hospitals in South Chennai, India - microbial profile, Indoor Built Environ., 17(5), 435-441.

Tang C.S, Chung F.F., Lin M.C., Wan G.H., Yuan T. and Kaohsiung (2009), Impact of patient visiting activities on indoor climate in a medical intensive care unit: a 1-year longitudinal study, Am J Infect Control, 37, 183-188.

Wan G.H., Chung F.F. and Tang C.S. (2011), Long-term surveillance of air quality in medical center operating rooms, Am J Infect Control, 39, 302-308. 